\title{
Voltage Control Performance of AWS Connected for Grid Operation
}

\author{
Biswarup Das, Member, IEEE, and Bikash C. Pal, Senior Member, IEEE
}

\begin{abstract}
A scheme for connecting a marine power plant (MPP) to a distribution grid in local shore is presented. In this scheme, power generated from two wave energy generators based on Archimedes wave swing (AWS) is fed through a combination of dc/dc converter and inverter to the grid. Suitable controls of the dc/dc converter and the inverter are suggested to ascertain satisfactory performance of the proposed scheme under different operating environments. The MPP is controlled to regulate the bus voltage of the grid. The performance of the scheme is demonstrated in detail through PSCAD/EMTDC simulation. The simulation resulting in two distribution networks show good transient performance of the MPP under different types of network faults. The level of harmonics generated by the MPP systems is also acceptable.
\end{abstract}

Index Terms-Archimedes wave swing (AWS), distributed generation, marine energy.

\section{INTRODUCTION}

$\mathbf{T}$ HE rise in global temperature due to increasing green house gas in the atmosphere and depletion of world fossil fuel resource are driving the pace of growth of renewable energy technology deployment. Even though the Kyoto protocol on climate change issues is not binding as of today, many countries in the world, through policy/legislations in national level are pursuing the option of meeting energy demand from renewable energy sources such as wind, solar, hydro, marine resources, biomass, CHP, etc. Among these, ocean wave energy has a vast potential, which is far from being commercially exploited. However, the theory and technology of wave energy conversion have been under study for quite a long time.

Clement et al. [1] have given a thorough account on the current status of the wave energy program in Europe. Mueller [2] has discussed various aspects of electrical generator used as wave energy converters. Dynamic analysis of a wave energy turbine driven grid-connected induction generator has been reported in [3]. In [4], simulation studies have been carried out for converting wave energy to electrical energy by a permanent magnet (PM) linear generator. Falnes has described the theoretical aspects of energy from ocean waves and oscillating water column (OWC) systems in [5]. Some strategies for controlling the rotational speed of a stand-alone OWC wave power plant have been described in [6]. However, hardly any research activity in integrating these generations to local distribution grid could be seen. Various options of storage devices (flywheel,

Manuscript received March 14, 2005; revised July 29, 2005. This work was supported by EPSRC (U.K.) under Grant GR/S28082/01. Paper no. TEC-000942005.

B. Das is with Department of Electrical Engineering, Indian Institute of Technology, Roorkee, India (e-mail: biswafee@iitr.ernet.in).

B. C. Pal is with Department of Electrical and Electronic Engineering, Imperial College, London, UK (e-mail: b.pal@imperial.ac.uk).

Digital Object Identifier 10.1109/TEC.2006.874220 battery) for stable power output to the grid from any general wave power plant have been discussed in [7]. While the authors in [7] focused on the advantages, limitation, and generic control philosophies, the detail demonstration of any technical scheme remains to be seen.

The concept of Archimedes wave swing (AWS) as a mechanism of converting wave energy to electrical energy was first introduced by Rademaker [8]. In an AWS, a floater is moved in a vertical plane due to the pressure exerted by the ocean waves, and subsequently, a three-phase linear PM generator is used to convert this energy of floater motion to electrical energy. Pollinder et al. in a very recent paper [9] have reported the design and experimental verification of a linear PM generator to extract power from the motion of wave through AWS. They are pursuing this concept further through a pilot demonstration project in Spanish coastal water as the first of its kind marine power plant (MPP). However, the integration and utilization of the extracted energy in the distribution grid apparently has not been reported in their paper.

We have proposed a scheme of connecting AWS-based MPP to distribution grid in this paper. The objective is to demonstrate a suitable grid connection methodology through detail electromagnetic transient simulation studies. It is assumed that the MPP can control the grid voltage. In anticipation of increased penetration of distributed generation (DG), the distribution grid operation codes in many countries are being reviewed to accommodate voltage control obligations from these generations. A possible scenario of active voltage control by DG is described in [10]. In our proposed scheme, we focus on a number of issues such as voltage control, power quality (harmonics), and fault performances, etc. Because of the problems associated with storage devices, the proposed scheme does not utilize any such device. The scheme is described next. The suggestions and conclusions are drawn on the basis of the results obtained from electromagnetic transient simulation software, PSCAD/EMTDC [11].

\section{System Description AND STEADY-STATE OPERATION}

The AWS generates a variable magnitude variable frequency (VMVF) voltage [9]. For ready reference, waveform of the phase-a voltage of an AWS [9] is shown in Fig. 1. Obviously, the AWS cannot be connected directly to the grid. A power converter shown in Fig. 2 is used to process the output of the AWS to a constant voltage constant frequency (CVCF) output suitable for grid connection. The AWS output is converted to dc by a rectifier and subsequently to ac by an inverter. The values of different components shown in Fig. 2 are given in the Appendix. A simple three-phase diode bridge rectifier (DBR) is used for 


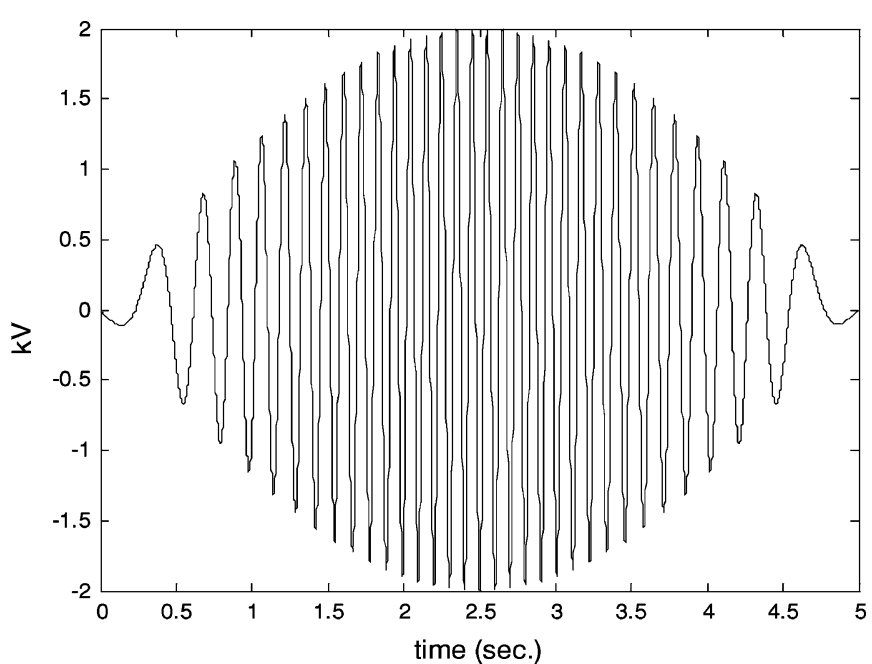

Fig. 1. No load phase voltage of AWS.

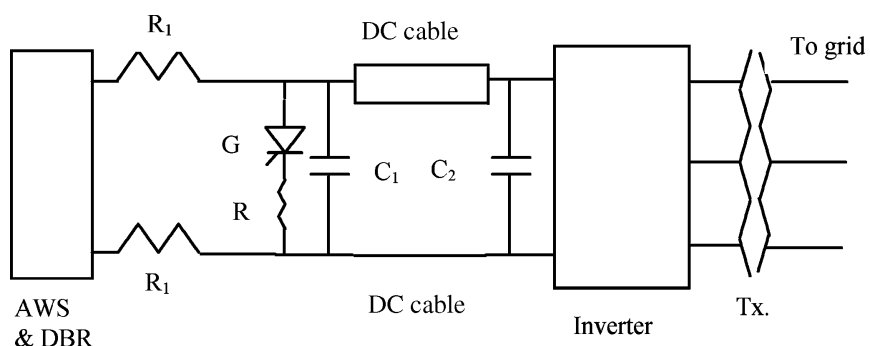

Fig. 2. A simple power conversion scheme.

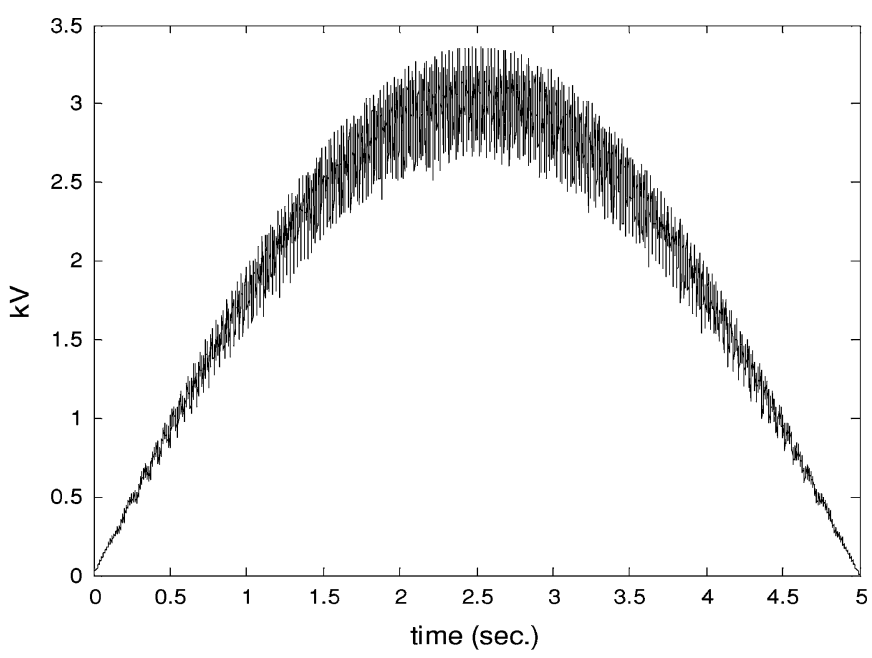

Fig. 3. $\quad V_{\mathrm{dr}}$ in the scheme shown in Fig. 2.

rectification. The AWS along with its DBR would be termed as MPP. The detail of the inverter scheme would be described later.

It can be seen in Fig. 1 that the AWS phase voltage becomes very low (i.e., almost equal to zero) in every $5 \mathrm{~s}$. This results in low dc output (virtually zero) at these instants. The waveform of the dc voltage across capacitor $\mathrm{C}_{1}$ supplying the inverter $\left(V_{\mathrm{dr}}\right)$ is shown in Fig. 3. Because of this highly fluctuating dc power, the inverter cannot supply constant real power to the grid.

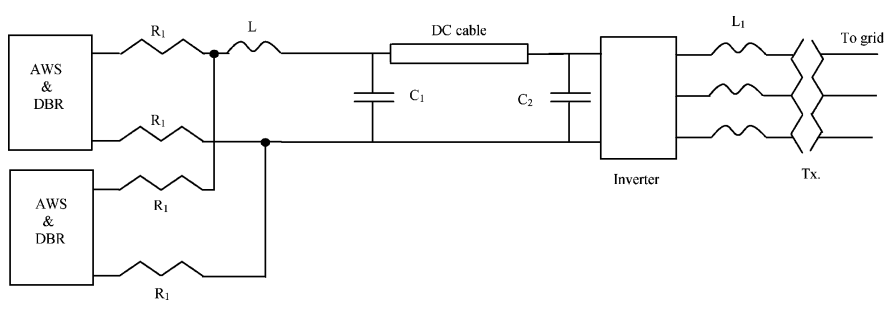

Fig. 4. A scheme employing two AWS.

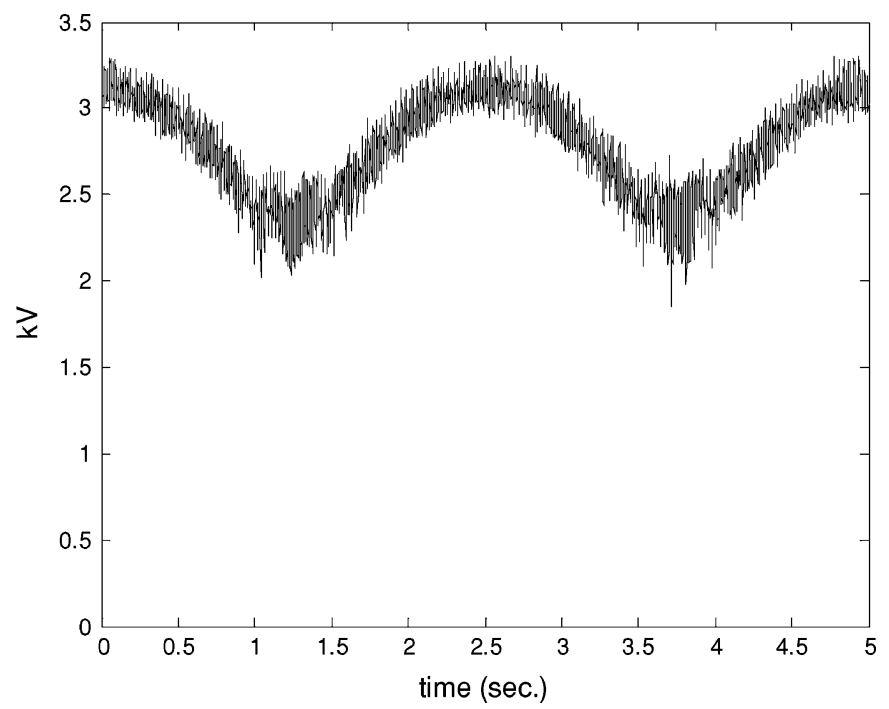

Fig. 5. $\quad V_{\mathrm{dr}}$ in the scheme shown in Fig. 4.

The problem can be addressed if the fluctuation of rectified voltage from MPP could be minimized with the help of another (second) AWS connected in parallel with the first AWS. Because of their physical distances, the voltage generated by the second AWS would be phaseshifted with respect to that of the first AWS. One such scheme is shown in Fig. 4. The combined rectified output voltage would be less fluctuating compared to that from one AWS only. This is observed in Fig. 5. The amount of increase in the minimum value of the common dc voltage would depend on the amount of phase shift between the two AWSs. Fig. 5 shows the waveform of the common dc bus voltage $\left(V_{\mathrm{dr}}\right)$ across capacitor $\mathrm{C}_{1}$ for an assumed phase shift of $90^{\circ}$ (maximum) between the two AWSs. This configuration with a suitable inverter and switching scheme can export power to the grid the maximum of which is dependent on the relative phase shift between two AWSs. Thus, it can be said that, for supplying constant real power to the grid, any AWS-based MPP should have at least two AWSs.

Once an acceptable value of minimum $V_{\mathrm{dr}}$ is obtained, a suitable inverter control strategy needs to be chosen. For this purpose, the standard SPWM technique [12] with a switching frequency of $1800 \mathrm{~Hz}$ was chosen to ensure a constant power to the grid from two AWSs combination. The feasibility of the scheme including inverter control is studied in a 17-bus, $12.66-\mathrm{kV}$, balanced three-phase radial distribution feeder model shown in Fig. 6. The MPP is treated as a PV bus. The power flow input data for this system is available in [13]. The feeder is 


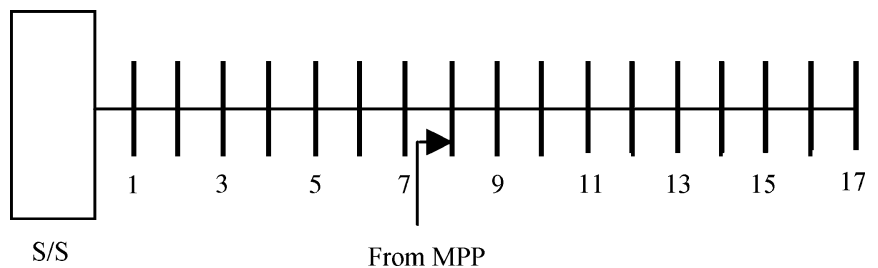

Fig. 6. 12.66-kV radial distribution feeder.

supplied by a $12.66-\mathrm{kV}$ substation and the system shown in Fig. 4 has been assumed to be connected at bus 8 of this feeder. The frequency of the sinusoidal modulating wave (corresponding to the SPWM scheme) of the inverter is locked to the frequency of the distribution system (measured at bus 8) by means of a PLL.

The SPWM-switching strategy helps to control the real power $P_{\mathrm{g}}$ supplied to the grid by changing the phase angle, $\delta$, of the sinusoidal modulating wave. The voltage of bus $8\left(V_{8}\right)$ is controlled by changing the modulation index $(m)$ of the inverter. Hence, two independent PI controllers have been used for controlling $\delta$ and $m$. The first PI controller (henceforth termed as "P-controller") calculates $\delta$ from the information of $\varepsilon_{\mathrm{g}}$ at its input where, $\varepsilon_{\mathrm{g}}=P_{\text {gref }}-P_{\mathrm{g}}, P_{\text {gref }}$ being the reference value of the real power (contracted amount of real power) supplied by the inverter. Similarly, the second PI controller (henceforth termed as "V-controller") calculates $m$ from the information of $\varepsilon_{\mathrm{v}}$ at its input where $\varepsilon_{\mathrm{v}}=V_{\text {ref }}-V_{8}, V_{\text {ref }}$ being the reference value of $V_{8}$.

Although $P_{\mathrm{g}}$ and $V_{8}$ can be controlled independently, the variation in one quantity indirectly affects the other one also. Moreover, in steady-state, it is highly desirable that the actual values of $P_{\mathrm{g}}$ and $V_{8}$ should be as close as possible to their corresponding reference values. Hence, the primary control objective of these two controllers is the minimization of steady-state errors in $P_{\mathrm{g}}$ and $V_{8}$. Based on this objective, the proportional gains and the integral time constants of these two controllers (let these be denoted as $K_{\mathrm{p}_{-} \mathrm{P}}, T_{\mathrm{i}_{-} \mathrm{P}}, K_{\mathrm{p}_{-}} \mathrm{V}, T_{\mathrm{i}_{-}} V$, respectively) are designed by minimizing the integral square error (ISE) measure as defined in (1). The minimization of this ISE measure has been carried out by using the "Simplex optimization" algorithm following the methodology described in [14].

$$
\mathrm{ISE}=\int_{0}^{T_{\mathrm{s}}}\left\{\left(P_{\text {gref }}-P_{\mathrm{g}}\right)^{2}+\left(V_{\text {ref }}-V_{8}\right)^{2}\right\} d t
$$

In (1), total simulation time $T_{\mathrm{s}}$ was chosen as $5 \mathrm{~s}$. Also, it is assumed that the MPP has agreed to supply $0.5 \mathrm{MW}$ of $P$, while $V_{8}$ is to be maintained at 1.0 p.u (thus, $P_{\text {gref }}=0.5$ and $V_{\text {ref }}=1.0$ ). The minimization of this ISE measure resulted in the following values of the control parameters: $K_{\mathrm{p}_{-} P}=-0.0002185, T_{\mathrm{i}_{-} P}=$ $0.000781491 \mathrm{~s}, K_{\mathrm{p}_{-}} V=-0.00092561, T_{\mathrm{i}_{-}} V=0.04978149 \mathrm{~s}$. With these parameters, the steady-state $P_{\mathrm{g}}$ and $V_{8}$ are shown in Fig. 7.

From Fig. 7 it is observed that even with the optimized control parameters, there are considerable fluctuations in $P_{\mathrm{g}}$ and some amount of fluctuations in $V_{8}$ around their desired steady-state values. This is due to the considerable steady-state variation of the input dc voltage of the inverter $\left(V_{\mathrm{dr}}\right.$, as shown in Fig. 5).

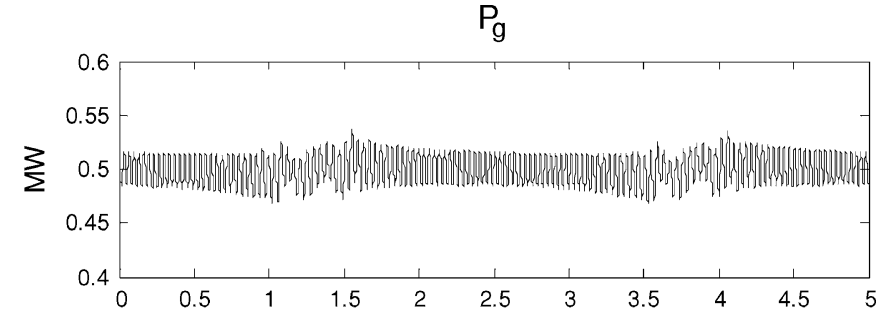

(a)

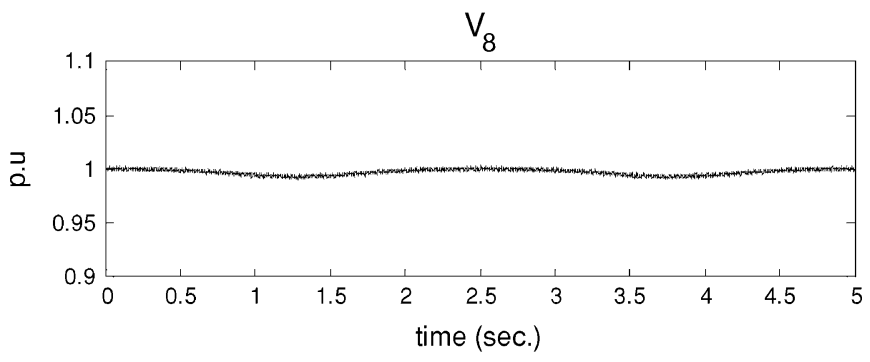

(b)

Fig. 7. Steady state $P_{\mathrm{g}}$ and $V_{8}$ for scheme in Fig. 4.

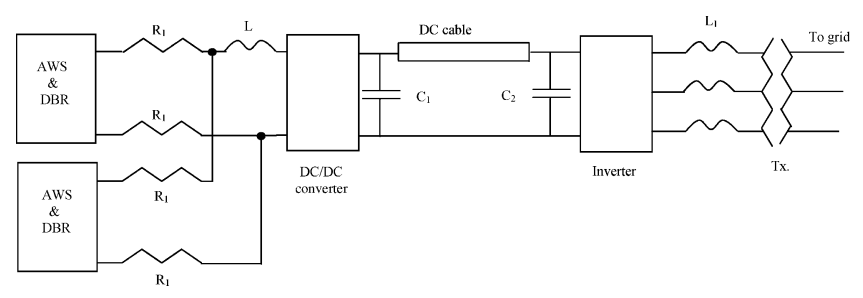

Fig. 8. Proposed scheme employing two AWSs.

Essentially, the controllers are not able to completely neutralize the impact of the variation in $V_{\mathrm{dr}}$, and as a result, some of the inverter input dc voltage variations also reach the inverter output quantities. Therefore, in maintaining constant $P_{\mathrm{g}}$ and $V_{8}$, it is necessary to maintain a constant $V_{\mathrm{dr}}$. For this purpose, a dc/dc boost converter is used just after the MPP and at the output of this dc/dc converter, the capacitor $\mathrm{C}_{1}$ is connected. The complete scheme is shown in Fig. 8. In this scheme, initially the fluctuating dc voltage (as shown in Fig. 5) is first converted to a constant dc voltage by the $\mathrm{dc} / \mathrm{dc}$ converter, which, in turn, supplies the inverter. Because of the constant dc voltage at its input, the inverter can be expected to maintain constant $P_{\mathrm{g}}$ and $V_{8}$.

The $\mathrm{dc} / \mathrm{dc}$ converter is controlled by a standard PWM scheme [12], in which the output voltage of the dc/dc converter is controlled by changing its modulation index $\left(m_{\mathrm{dc}}\right)$. Hence, another PI controller (henceforth termed as "dc-controller") is used, which calculates " $m_{\mathrm{dc}}$ " from the information of $\varepsilon_{\mathrm{dc}}$ at its input where $\varepsilon_{\mathrm{dc}}=V_{\mathrm{dcref}}-V_{\mathrm{dr}} . V_{\mathrm{dcref}}$ is the reference value of the $\mathrm{dc}$ voltage across capacitor $\mathrm{C}_{1}$. A value of $4 \mathrm{kV}$ was chosen for $V_{\mathrm{dcref}}$. Moreover, as $V_{\mathrm{dr}}, P_{\mathrm{g}}$, and $V_{8}$ influence each other, the parameters of the "dc-controller," designated as $K_{\mathrm{p} \_\mathrm{dc}}$ and $T_{\mathrm{i}_{-} \mathrm{dc}}$, were required to be designed in conjunction with those of the "P-controller" and "V-controller." All these six controller parameters are designed by minimizing the ISE measure given in (1) and the minimization of this measure has been carried out by the same procedure described above. 


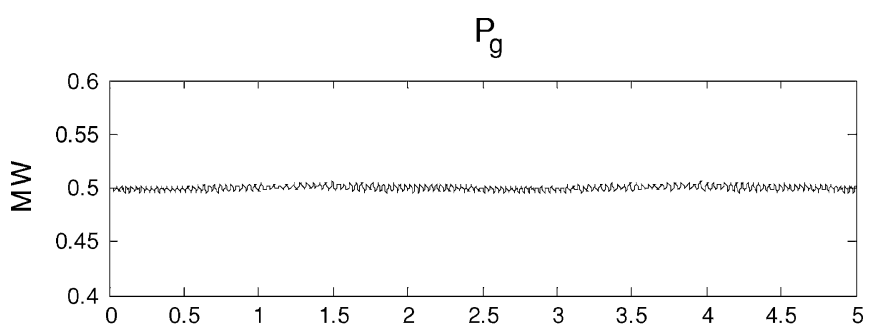

(a)

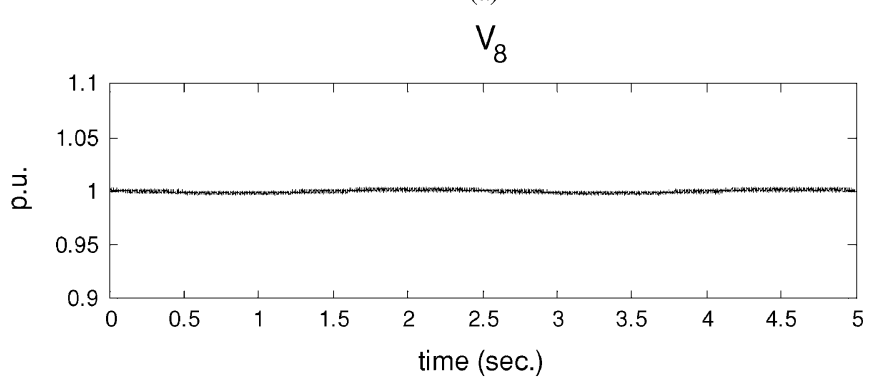

(b)

Fig. 9. Steady-state $P_{\mathrm{g}}$ and $V_{8}$ for scheme in Fig. 8 .

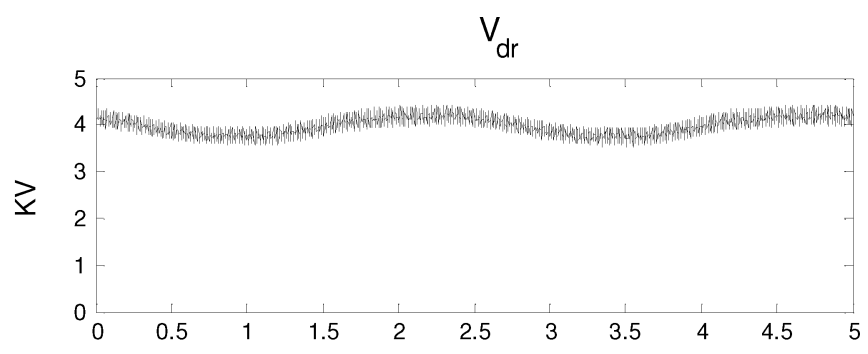

(a)

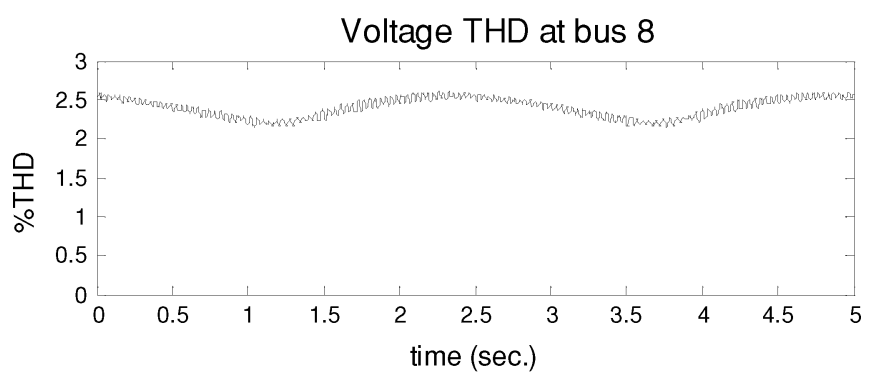

(b)

Fig. 10. $\quad V_{\mathrm{dr}}$ and voltage THD for scheme in Fig. 8.

The following controller parameters were obtained from the optimization task: $K_{\mathrm{p}_{-}} P=-0.00019395, T_{\mathrm{i}_{-}} P=$ $0.00080604 \mathrm{~s}, K_{\mathrm{p}_{-}} V=-0.00019395, T_{\mathrm{i}_{-}} V=0.0490989 \mathrm{~s}$, $K_{\mathrm{p \_ dc}}=0.19980604$, and $T_{\mathrm{i}_{\mathrm{d}} \mathrm{dc}}=0.49980604 \mathrm{~s}$. The traces of $P_{\mathrm{g}}$ and $V_{8}$ are shown in Fig. 9, while the time variation of the total harmonic distortion (THD) of the voltage of bus 8 and $V_{\mathrm{dr}}$ are shown in Fig. 10. Comparison of Figs. 5 and 10(a) shows that the $\mathrm{dc} / \mathrm{dc}$ converter helps to reduce the fluctuation in $V_{\mathrm{dr}}$ considerably, which in turn, enables the inverter to maintain an acceptable constant level of $P_{\mathrm{g}}$ and $V_{8}$ at its output (as observed from the comparison of Figs. 7 and 9). Moreover, the THD, as revealed in Fig. 10(b) is well within the prescribed acceptable limit of 5\% according to IEEE standard 519-1992 [12]. So, the

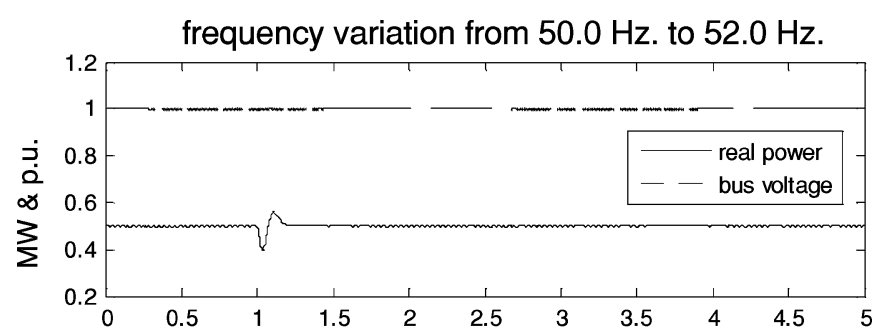

(a)

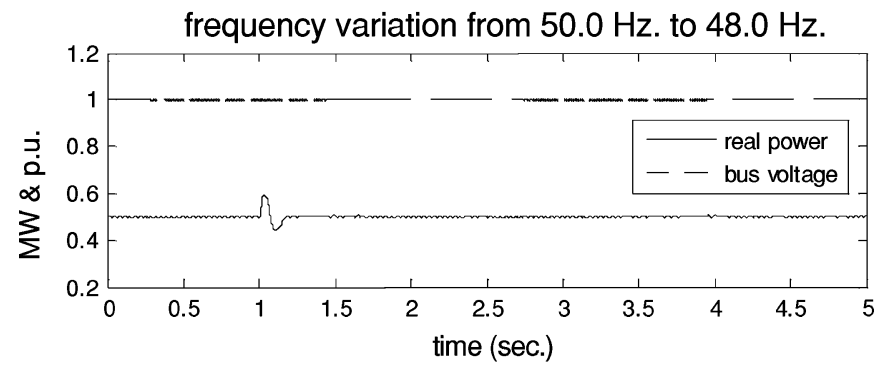

(b)

Fig. 11. System performance with grid frequency variation.

TABLE I

Details of the Command Set Points in $P_{\mathrm{g}}(\mathrm{MW})$

\begin{tabular}{|c|c|c|c|c|c|}
\hline $\begin{array}{c}\text { Time } \\
(\mathrm{sec} .)\end{array}$ & $\begin{array}{c}\text { Existing } \\
\mathrm{P}_{\mathrm{g}}\end{array}$ & $\begin{array}{c}\text { Command } \\
\mathrm{P}_{\mathrm{g}}\end{array}$ & $\begin{array}{c}\text { Time } \\
(\mathrm{sec} .)\end{array}$ & $\begin{array}{c}\text { Existing } \\
\mathrm{P}_{\mathrm{g}}\end{array}$ & $\begin{array}{c}\text { Comman } \\
\mathrm{d}_{\mathrm{g}}\end{array}$ \\
\hline 0.5 & 0.5 & 0.7 & 1.5 & 0.7 & 0.3 \\
\hline 2.5 & 0.3 & 0.6 & 3.5 & 0.6 & 0.4 \\
\hline 4.5 & 0.4 & 0.5 & - & - & - \\
\hline
\end{tabular}

arrangement shown in Fig. 8 can be considered as a suitable scheme for utilizing the MPP as a PV source.

Simulation studies were carried out assuming step changes in the substation grid frequency to investigate the performance of the proposed scheme on the event of grid frequency variation. Fig. 11 shows the simulation results. In this figure, it is assumed that the values of contracted $P_{\text {ref }}$ and $V_{\text {ref }}$ are $0.5 \mathrm{MW}$ and 1.0 p.u, respectively and the frequency step change occurs at $t=1.0 \mathrm{~s}$. Fig. 11(a) shows the results when the frequency is changed from 50.0 to $52.0 \mathrm{~Hz}$. Fig. 11(b) shows the results when the frequency is changed from 50.0 to $48.0 \mathrm{~Hz}$. It is observed that with step changes in the grid frequency, $P_{\mathrm{g}}$ also deviates instantaneously from its desired value. This is due to the mismatch between the grid frequency and the frequency of the inverter modulation wave. After a short period, the frequency of the inverter modulation wave is locked to the new grid frequency through PLL, and $P_{\mathrm{g}}$ also returns to its desired level. The change in grid frequency has a negligible effect on $V_{8}$.

The ability of the inverter to follow step changes in its desired values of output $P_{\mathrm{g}}$ is investigated with the changes in set point commands in $P_{\mathrm{g}}$ at various time instants. The details of the changes in the set point commands are given in Table I. Fig. 12(a) and (b) shows the variations of the real power supplied by the inverter and substation, respectively, for the step changes in the set point commands in $P_{\mathrm{g}}$. It is noted from theses figures that the output $P_{\mathrm{g}}$ of the inverter independently follows the command $P_{\mathrm{g}}$ with high accuracy. Thus, even though individual AWS produces variable power, Fig. 12 shows that it 


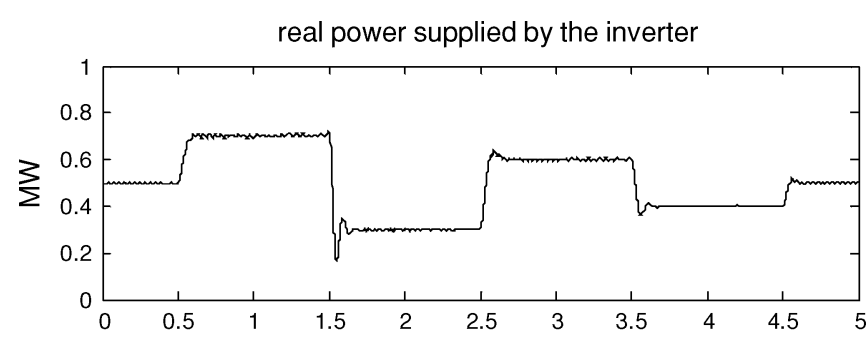

(a)

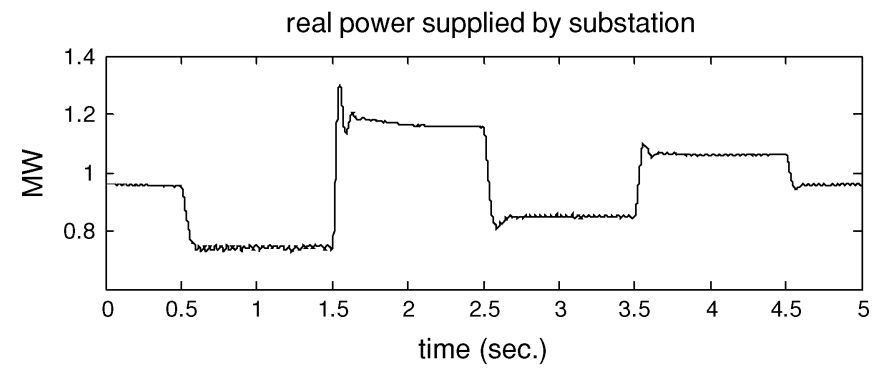

(b)

Fig. 12. Performance for step changes in $P$ command.

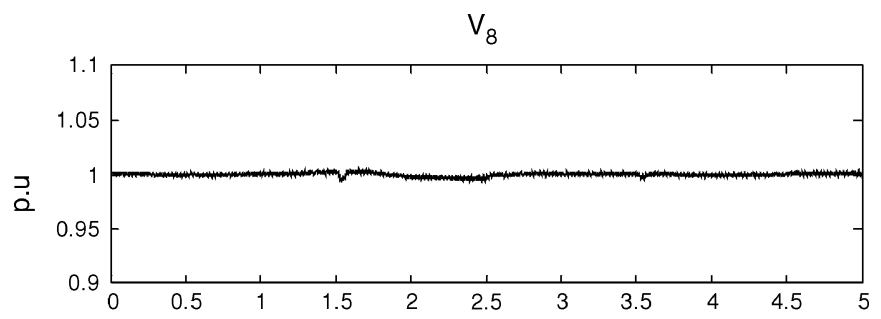

(a)

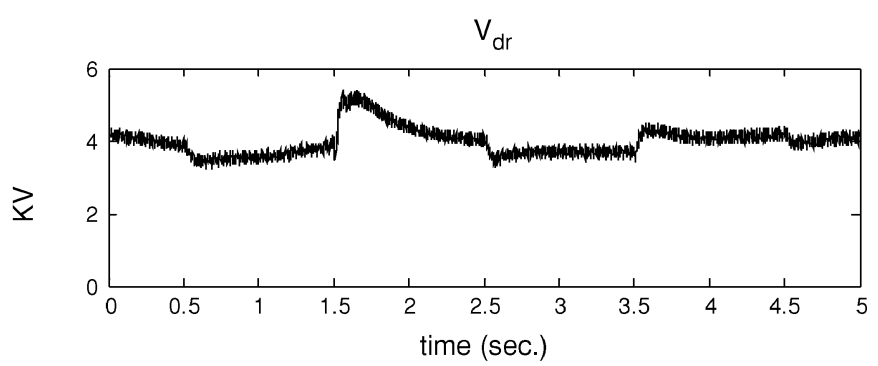

(b)

Fig. 13. $V_{8}$ and $V_{\mathrm{dr}}$ for step changes in $P$ command.

is possible to supply constant real power to the grid from the MPP. Moreover, as the contracted $P_{\mathrm{g}}$ changes, the real power supplied by the inverter also changes automatically to maintain the balance between the total supply and total demand (i.e., load plus loss).

Fig. 13 shows the variation of $V_{8}$ and $V_{\mathrm{dr}}$ for this case. It is observed that the inverter is able to maintain the system bus voltage at the desired level even with a considerable variation in its real power output. However, when $P_{\mathrm{g}}$ is suddenly increased (decreased), $V_{\mathrm{dr}}$ decreases (increases) momentarily due to the imbalance between the input power and the output power to the dc capacitor, which is subsequently brought back to its desired level $(4.0 \mathrm{kV})$ by the $\mathrm{dc} / \mathrm{dc}$ converter control.

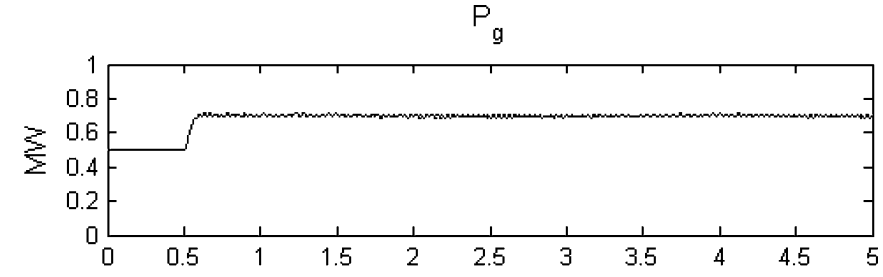

(a)

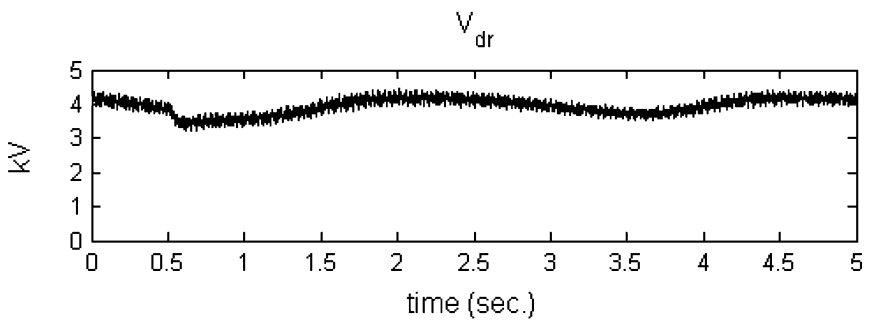

(b)

Fig. 14. $\quad P_{\mathrm{g}}$ and $V_{\mathrm{dr}}$ for sustained changes in $P$ command.

The performance of the proposed scheme for a sustained step increase in the desired value of $P_{\mathrm{g}}$ is shown in Fig. 14. In this case, it is assumed that at $t=0.5 \mathrm{~s}$, the desired value of output $P_{\mathrm{g}}$ supplied by the MPP was enhanced from 0.5 to $0.7 \mathrm{MW}$. Fig. 14(a) shows the variation of $P_{\mathrm{g}}$ while the variation of $V_{8}$ for this case is depicted in Fig. 14(b). It is observed that, in spite of cyclic variation of dc voltage at the output of the bridge rectifiers (shown in Fig. 5), the dc/dc converter is able to maintain $V_{\mathrm{dr}}$ at the specified level by extracting extra power from the two AWS and, in this process, the output power is maintained at the enhanced level on a sustained basis. However, it is to be noted that for a significantly higher value of step increase, the capability of the AWS, dc/dc converter, and the inverter may not be sufficient enough to maintain the output real power at the enhanced level on a continuous basis.

\section{TRANSIENT PERformance}

Several fault studies have been carried out in the distribution feeder to investigate the transient performance of the proposed scheme. For this purpose, the fault duration and the fault resistance have been assumed to be 5 cycles (i.e., $0.1 \mathrm{~s}$ ) and $0.0 \mathrm{ohm}$, respectively. Also, the steady-state grid frequency and the specified voltage of bus 8 have been assumed to be $50 \mathrm{~Hz}$ and 1.0 p.u., respectively. Moreover, for the fault cases presented below, until otherwise specified, the prefault steady-state contracted power is assumed to be $P_{\mathrm{g}}=0.5 \mathrm{MW}$.

Fig. 15 shows the system response for a $3 \mathrm{LG}$ fault at bus 9 (which is the closest bus to the "MPP bus" at its downstream side) occurring at $t=1.0 \mathrm{~s}$. Similarly, the response for a $3 \mathrm{LG}$ fault at bus 7 (which is the closest bus to the "MPP bus" at its upstream side) occurring at $t=1.0 \mathrm{~s}$ is shown in Fig. 16. During a $3 \mathrm{LG}$ fault, both $P_{\mathrm{g}}$ and $V_{8}$ reduce considerably. Once the fault is cleared, $P_{\mathrm{g}}$ undergoes a steep upward transient swing before coming back to the prefault steady-state level. These significant oscillations in $P_{\mathrm{g}}$ also cause $V_{\mathrm{dr}}$ to oscillate before returning to its normal steady-state level. However, in spite of the severe 


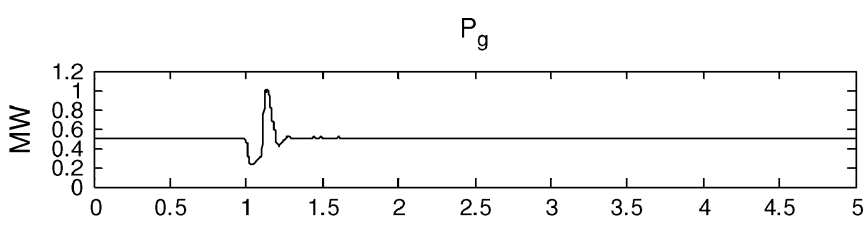

(a)

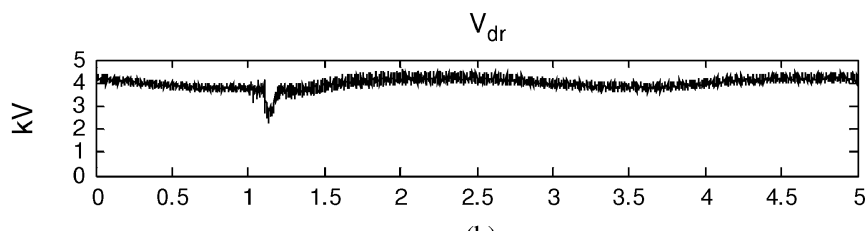

(b)

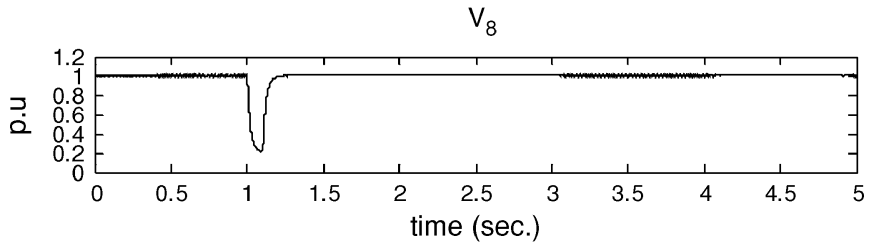

(c)

Fig. 15. System performance for a $3 \mathrm{LG}$ fault at bus 9 occurring at $t=1.0 \mathrm{~s}$.

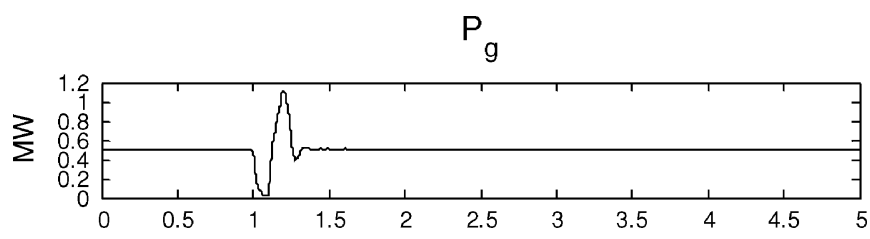

(a)

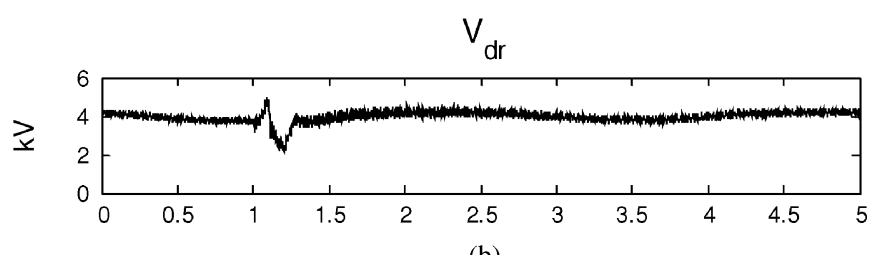

(b)

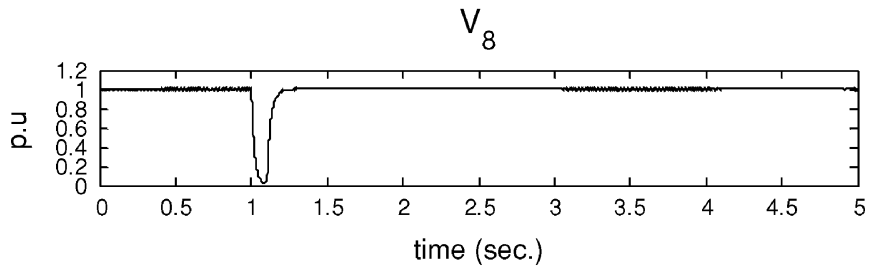

(c)

Fig. 16. System performance for a $3 \mathrm{LG}$ fault at bus 7 occurring at $t=1.0 \mathrm{~s}$.

mismatch between the input power and the output power to the dc capacitor during these transient periods, the dc/dc converter is able to maintain $V_{\mathrm{dr}}$ around $4.0 \mathrm{kV}$. On the other hand, $V_{8}$ returns to its normal steady-state level upon clearing of the fault without any appreciable transient.

The robustness of the proposed scheme has been studied at an increased power output from the inverter for various fault cases. For this purpose, the inverter is now assumed to supply $0.6 \mathrm{MW}$ of real power to the grid (i.e., $P_{\mathrm{g}}=0.6$ ). Figs. $17-20$ show the simulation results for different types of faults at bus 9 and at

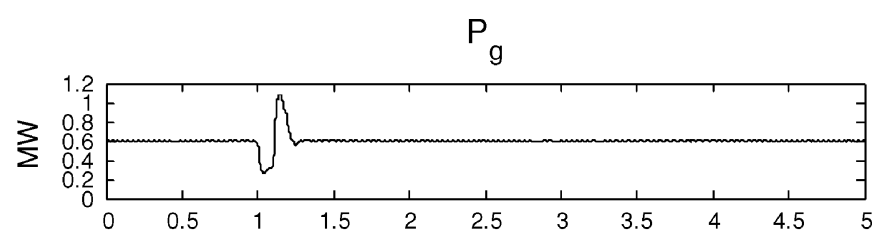

(a)

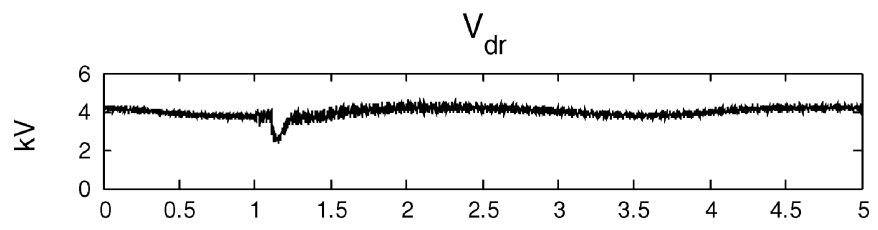

(b)

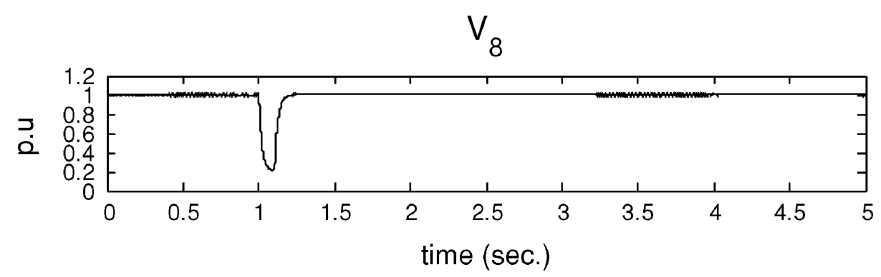

(c)

Fig. 17. System performance for a 3LG fault at bus 9 (with $P_{\mathrm{g}}=0.6 \mathrm{MW}$ ) occurring at $t=1.0 \mathrm{~s}$.

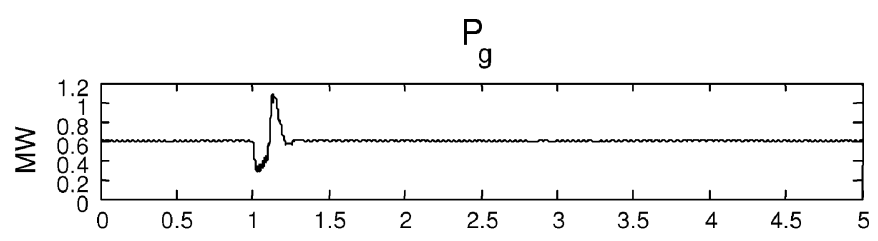

(a)

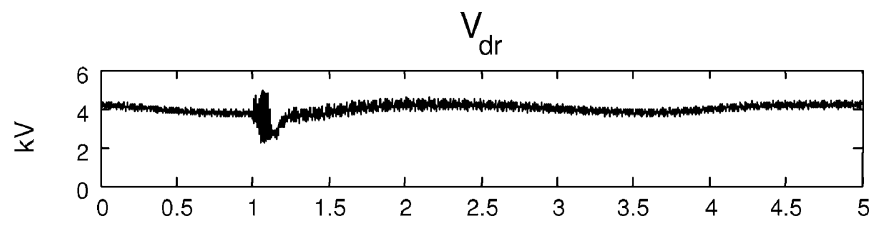

(b)

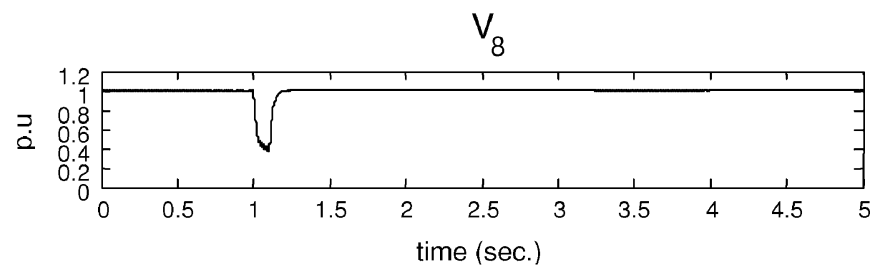

(c)

Fig. 18. System performance for an LLG fault at bus 7 (with $P_{\mathrm{g}}=0.6 \mathrm{MW}$ ) occurring at $t=1.0 \mathrm{~s}$.

bus 7 where it is observed that the proposed scheme performs satisfactorily under various types of faults at an elevated power level also.

Now, buses 7 and 9 are essentially the "adjacent" buses to the "MPP bus." For faults occurring at any bus other than the adjacent buses, as the electrical distance of the fault from the MPP is more (compared to the distance of a fault at any of 


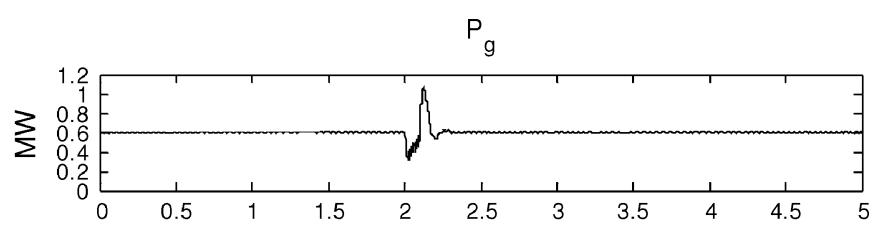

(a)

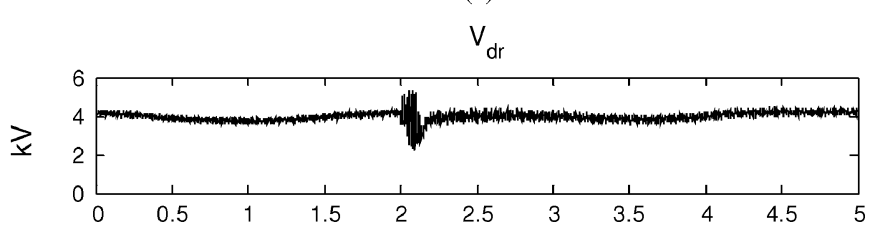

(b)

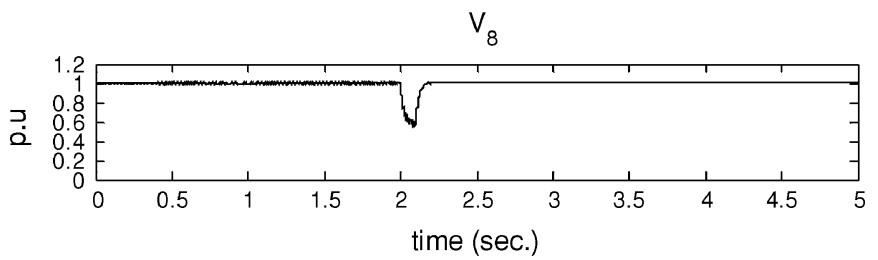

(c)

Fig. 19. System performance for an LL fault at bus 7 (with $P_{\mathrm{g}}=0.6 \mathrm{MW}$ ) occurring at $t=2.0 \mathrm{~s}$.

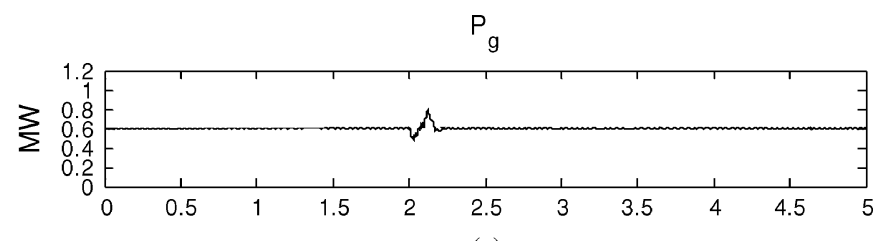

(a)

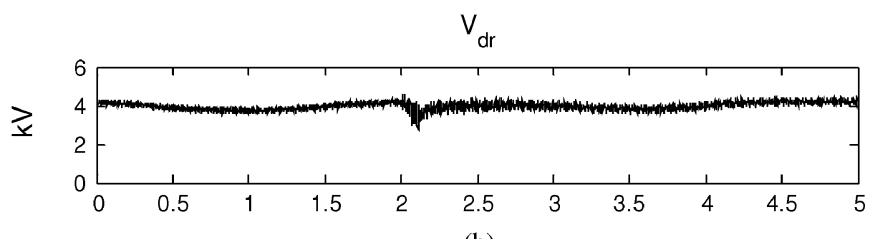

(b)

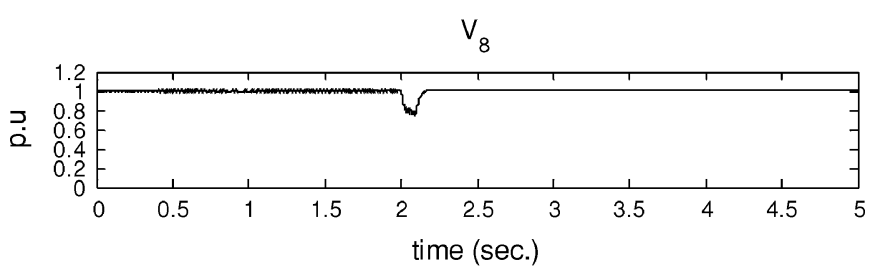

(c)

Fig. 20. System performance for an LG fault at bus 9 (with $P_{\mathrm{g}}=0.6 \mathrm{MW}$ ) occurring at $t=2.0 \mathrm{~s}$.

the "adjacent" buses to the MPP), the impact of these faults is less on the MPP. Hence, the performance of the MPP upon the occurrence of these faults is also quite acceptable, and as a result, these results are not replicated in this paper. Hence, for faults at these buses, the MPP should stay connected to the grid to provide the much needed ride through capabilities of the DG. This also helps to prevent the over voltage across the dc link capacitor.

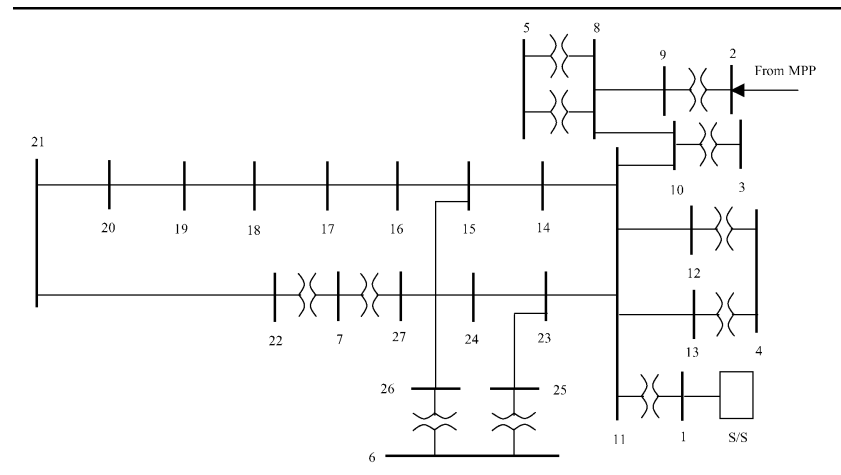

Fig. 21. A small segment of the U.K. distribution system.

\section{Results in a Practical Network Model AND DISCUSSIONS}

The effectiveness of the proposed scheme was further validated in a small portion of U.K. distribution network as shown in Fig. 21. This network is a segment of South Eastern England distribution grid nearer to the coast where the future potential of integration of wave energy is high. The lines, cables, transformers, power flow, and fault level information are representative of realistic system-operating situation. The data are supplied by the EDF energy (EDFE), the distribution network company that owns and operates the system in London and South East of England. The bus location for MPP connection was selected from the power flow solution on the system model. Based on the findings of this study, bus 2 in Fig. 21 has been chosen to be the MPP bus as it has the lowest voltage.

Because of low voltage at bus 2 , significant amount of reactive power need to come from MPP to bus 2 to elevate its voltage to the rated value (1.0 p.u.). The short circuit MVA at this bus is 98 MVA. This needed a high inverter output voltage, which in turn demands a high input dc voltage of the inverter $\left(V_{\mathrm{dr}}\right)$. Thus, the value of $V_{\mathrm{dcref}}$ needed for the system shown in Fig. 21 is higher than the value required for the system shown in Fig. 6. From detail study of this system, it has been found that a value of $12 \mathrm{kV}$ for $V_{\text {dcref }}$ is adequate for maintaining the voltage of the "MPP bus" at the rated value. Also, as before, it has been assumed that $0.5 \mathrm{MW}$ of real power has been contracted to be supplied from the MPP to the grid. For this operating point, described by $P_{\text {gref }}=0.5, V_{\text {ref }}=1.0$, and $V_{\text {dcref }}=12.0$, the controller parameters have been designed by the same optimization procedure described in Section II. The steady-state behavior of the system is shown in Fig. 22.

It is observed from the results shown in Fig. 22 that the performance of the proposed scheme is quite acceptable. Moreover, several fault studies have also been carried out to assess the transient performance of the scheme on this practical system. For this purpose, the faults have only been considered at the closest bus (bus 9 in Fig. 21) to the "MPP bus" and the faults were assumed to occur at $t=1.0 \mathrm{~s}$. The prefault operating point was assumed to be the same as that shown in Fig. 21 and the values of $\mathrm{S} / \mathrm{S}$ frequency, fault duration, and fault resistance have been assumed as $50 \mathrm{~Hz}, 0.1 \mathrm{~s}$ and $0.0 \mathrm{ohm}$, respectively. Figs. 23 and 24 show the responses for $3 \mathrm{LG}$ fault and $1 \mathrm{LG}$ fault, respectively. 


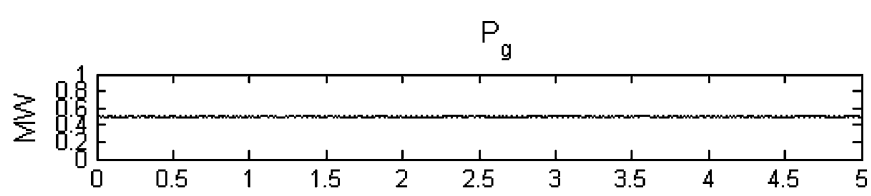

(a)

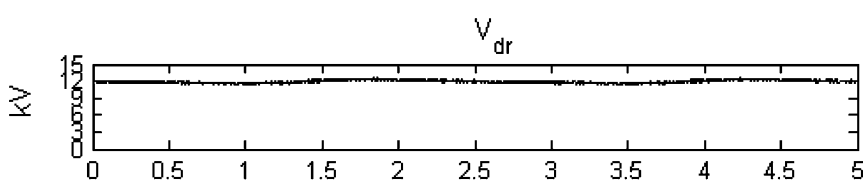

(b)

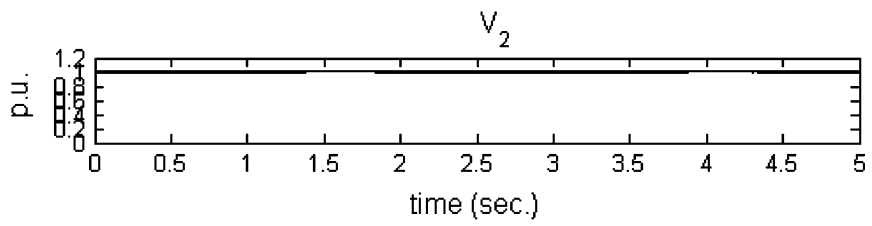

(c)

Fig. 22. Steady-state performance in the U.K. grid.
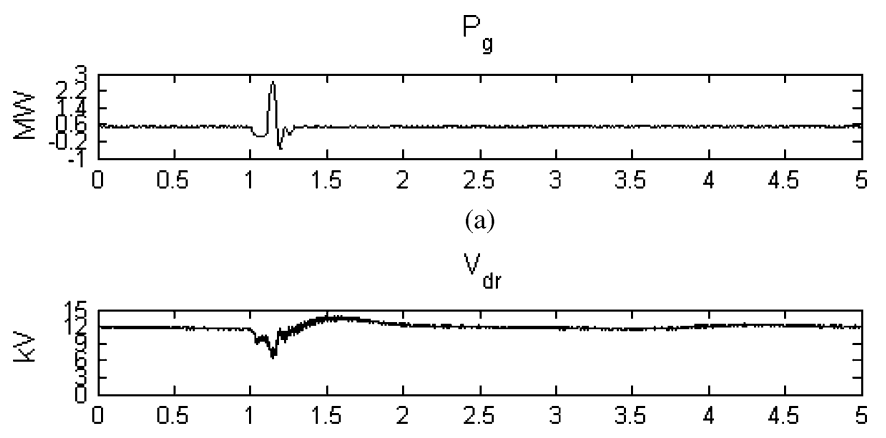

(b)

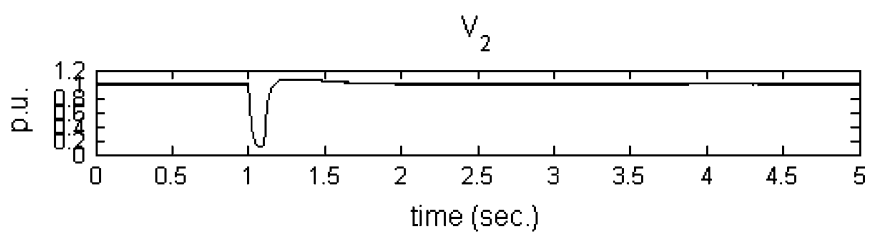

(c)

Fig. 23. Performance for a $3 L G$ fault in the U.K. grid.

From these figures, it is observed that the proposed scheme performs quite satisfactorily upon occurrence of faults in the practical grid also.

The proposed scheme has demonstrated to offer impressive performance in two system models. However, from the perspective of practical implementation, few important related issues must be kept in the mind. These are discussed below.

1) A finite phase difference (assumed $90^{\circ}$ in this paper) must exist between two AWSs. This is possible as long as two AWSs do not experience the same wave at the same time, i.e., the distance between them is not integral multiple of the wavelength. However, the property of a wave varies with atmospheric conditions, weather patterns, and seasonal variations. Hence, it is difficult to exactly calculate the required distance for a given amount of phase shift.

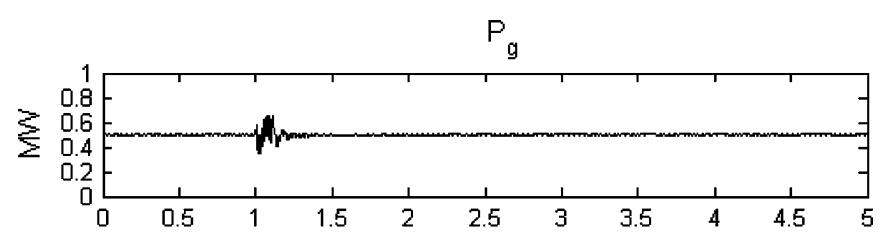

(a)

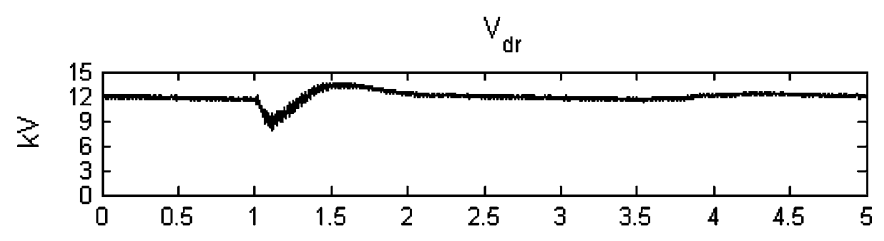

(b)

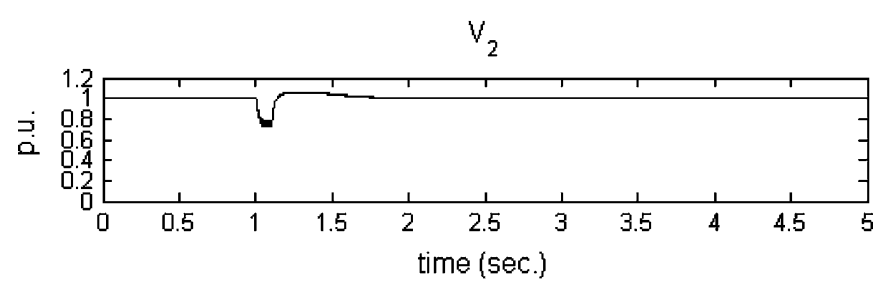

(c)

Fig. 24. Performance for a 1LG fault in the U.K. grid.

However, from the statistical information of the wave gathered over many years, some approximate idea about the frequency can be very roughly guessed to decide the distance between two AWS for a given amount of finite phase shift. In practice, a large number of AWSs (say 5 or 6 ) may be installed in a wave energy park to ensure that, at any given instant, some phase shift exists between at least two of them. Although, in principle, the above philosophy appears to be fine, but frankly, the practical issues are really quite challenging.

2) In this paper, two AWSs have been connected in parallel. Now, the dc output voltage from an AWS-DBR is quite low during the first and last one seconds in the cycle as can be seen from Fig. 3. The power conversion system under this situation cannot sustain constant power output to the grid. This led us to go for two AWSs operating in parallel and time shifted. If two AWSs are connected in series, then the stator of each AWS in that case needs to be designed to carry high RMS current continuously. The output voltage of each AWS will be reduced but the insulation of each AWS needs to be designed for total circuit voltage. Moreover, the problem of series operation is reliability; if one AWS is taken out for maintenance or fault, there would be interruption of supply. This is of less possibility in parallel operation mode and, in fact, of no possibility when more than two AWSs operate in parallel.

3) One of the most important considerations before practical implementation is cost. At the present level of prices of the different devices, the total cost of the power electronic components of the proposed scheme can be worked out to be roughly equal to $\mathcal{E} 0.3$ million. Clearly, the power conversion equipment cost is not at all competitive 
to conventional plant, such as combined cycle gas turbine (CCGT), large hydro, and coal. However, the cost of semiconductor devices has been following downward trends. Moreover, the local government is expected to subsidize part of the connection cost through national or regional renewable energy programme. In the U.K., two incentives are already in place for the DG to connect to the grid. These are: a) registered power zone (RPZ) and b) renewable obligation certificate (ROC). About $\mathcal{E} 4.5$ per MW of installed capacity is paid to DG owners with an upper cap of $\mathcal{E} 0.5 \mathrm{M}$. Revenue earned through selling ROC to fossil-fuel-based power companies are passed on to DG as incentive. This is expected to give much needed incentive for investment in DG. Also, with mass production and scaling of AWS, the cost is expected to come down in future. Nevertheless, under current trading environment, AWS cannot face the market competition. However, the scheme is technically feasible but not commercially viable at present. The research described in the paper is part of U.K. sustainable energy programme with an objective that in the long term (2040 and beyond), a significant portion of the nation's energy needs would be met from marine energy resources.

\section{CONCLUSION}

In this paper, a grid connection methodology for an AWSbased MPP is proposed. The MPP is controlled to regulate the bus voltage of the grid. The findings of this paper can be summarized as below.

1) At least two AWSs are necessary in the MPP to supply power to the grid at a specified level.

2) An intermediate dc/dc converter stage is required to maintain an acceptable constant level of real power output from the inverter.

3) The proposed scheme is able to maintain the distribution bus voltage at the required level quite tightly.

4) During transient conditions, the dc/dc converter also helps to limit the voltage stress across the dc capacitors.

\section{APPENDIX}

System data (for Figs. 2, 4, and 8)

$R_{1}=0.5 \mathrm{ohm}, C_{1}=C_{2}=1000 \mu \mathrm{F} ; R=1.0 \mathrm{ohm} ; L=0.01$ $\mathrm{H} ; L_{1}=0.001 \mathrm{H}$; DC link parameters [15]: $R_{\mathrm{dc}}=0.0647 \mathrm{ohm}$, $L=5.27 \mathrm{e}-5 \mathrm{H}$; Tx. Parameters: $50 \mathrm{~Hz}, 1.0 \mathrm{MVA}, 0.24 / 12.66$ $\mathrm{kV}, X=10 \%$.

\section{REFERENCES}

[1] A. Clement et al., "Wave energy in Europe: Current status and perspective," Renew. Sustain. Energy Rev., vol. 6, no. 5, pp. 405-431, Oct. 2002.

[2] M. A. Mueller, "Electrical generators for direct drive wave energy converters," IEEE Proc. Generation, Transmission Distribution, vol. 149, no. 4, pp. 446-456, Jul. 2002.
[3] S. S. Y. Narayanan, B. K. Murthy, and G. S. Rao, "Dynamic analysis of grid-connected induction generator driven by a wave-energy turbine through hunting network," IEEE Trans. Energy Convers., vol. 14, no. 1, pp. 115-120, Mar. 1999.

[4] M. Leijon et al., "Multiphysics simulation of wave energy to electric energy conversion by permanent magnet linear generator," IEEE Trans. Energy Convers., vol. 20, no. 1, pp. 219-224, Mar. 2005.

[5] J. Falnes, Ocean Waves and Oscillating Systems: Linear Interaction Including Wave Energy Extraction. Cambridge, U.K.: Cambridge Univ. Press, 2002.

[6] P. A. P. Justino and A. F. D. O. Falcao, "Rotational speed control of an OWC wave power plant," J. Offshore Mech. Arctic Eng., vol. 121, no. 2, pp. 65-70, May 1999.

[7] W. C. Beattie, G. Peters, and R. G. Alcorn, "Strategies for the control of a wave power station with a semiconductor converter," in Proc. 2nd Eur: Wave Power Conf., Lisbon, Portugal, 1995.

[8] L. W. M. M. Rademekers, R. G. Van Schie, R. Schuitema, B. Vriesema, and F. Gardner, "Physical model testing for characterising the AWS," in Proc. Eur. Wave Energy Conf., Patras, Greece, 1998.

[9] H. Pollinder, M. E. C. Damen, and F. Gardner, "Linear PM generator system for wave energy conversion in the AWS," IEEE Trans. Energy Convers., vol. 19, no. 3, pp. 583-589, Sep. 2004.

[10] M. H. J. Bollen and A. Sannino, "Voltage control with inverter based distributed generation," IEEE Trans. Power Del., vol. 20, no. 1, pp. 519520, Jan. 2005.

[11] PSCAD/EMTDC Version 4.01, Manitoba HVDC Research Center, 244 Cree Crescent, Winnipeg, Manitoba, Canada-R3J 3W1.

[12] N. Mohan, T. M. Undeland, and W. P. Robbins, Power Electronics: Converters, Applications and Design. New York: Wiley, 1989.

[13] M. E. Baran and F. F. Wu, "Network reconfiguration in distribution systems for loss reduction and load balancing," IEEE Trans. Power Del., vol. 4 no. 2, pp. 1401-1407, Apr. 1989.

[14] A. M. Gole, S. Filizadeh, R. W. Menzies, and P. L. Wilson, "Optimization-Enabled electromagnetic transient simulation," IEEE Trans. Power Del., vol. 20, no. 1, pp. 512-518, Jan. 2005.

[15] P. Karlsson and J. Svensson, "DC bus voltage control for a distributed power system," IEEE Trans. Power Electron., vol. 18, no. 6, pp. 14051412, Nov. 2003.

Biswarup Das (M'02) received the B.E.E. (Hons.) and M.E. degrees from Jadavpur University, Calcutta, India, in 1989 and 1991, respectively, and the Ph.D. degree in electrical engineering from Indian Institute of Technology Kanpur, Kanpur, India, in 1998, with specialization in electric power system.

Since 1998, he has been with the Department of Electrical Engineering, IIT Roorkee, India, where he is presently an Assistant Professor. During 20042005, he has worked for the Imperial College London as a Research Associate. His current research interests are in the area of FACTS, distribution automation, distributed generation, and renewable energy sources.

Bikash C. Pal (M'00-SM'02) received the B.E.E. (Hons.) degree from Jadavpur University, Calcutta, India, and the M.E. degree from the Indian Institute of Science, Bangalore, India, in 1990 and 1992, respectively, and the Ph.D. degree from the Imperial College London, London, U.K., in 1999.

$\mathrm{He}$ is presently a Senior Lecturer in the Department of Electrical and Electronic Engineering, Imperial College London. His research interests are in the area of power system dynamics and FACTS controllers, distributed generation, and modeling and control of renewable energy sources. 